\title{
Low Temperature Electrochemical Synthesis of Nanostructured ZrC Powder in Molten Salt
}

\author{
Hongxia Liu ${ }^{1, *}$, Weihao Song ${ }^{1}$, Qian $\mathrm{Xu}^{2, *}$,Wen $\mathrm{Ma}^{1}$, Yu Bai ${ }^{1}$ \\ ${ }^{1}$ School of Materials Science and Engineering, Inner Mongolia University of Technology, Inner \\ Mongolia Key Laboratory of Thin Film and Coatings, Hohhot 010051, Inner Mongolia, PR China \\ ${ }^{2}$ State Key Laboratory of Advanced Special Steel, Shanghai University, Shang hai 200072, PR China. \\ *E-mail: pghx@163.com, qianxu@shu.edu.cn
}

doi: $10.20964 / 2020.07 .17$

Received: 2 March 2020 / Accepted: 14 April 2020 / Published: 10 June 2020

\begin{abstract}
$\mathrm{ZrC}$ powder was directly electrosynthesized from inexpensive $\mathrm{ZrO}_{2}$ and carbon black precursors in molten $\mathrm{CaCl}_{2}-\mathrm{NaCl}$ at $800{ }^{\circ} \mathrm{C}$. Constant voltage electrolysis was applied at $3.1 \mathrm{~V}$ between a graphite anode and a cathode composed of a $\mathrm{ZrO}_{2} /$ carbon mixture. The reaction pathway of the solid state reduction was investigated by characterizing the composition and microstructure of partially and fully reduced samples. The spontaneous formation of the intermediate compound $\mathrm{CaZrO}_{3}$ was studied by an immersion experiment and thermodynamic analysis. The results show that the as-synthesized $\mathrm{ZrC}$ was composed of spherical particles with an average particle size of roughly $50 \mathrm{~nm}$. The reduction pathway started by converting $\mathrm{m}-\mathrm{ZrO}_{2}$ to $\mathrm{CaZrO}_{3}, \mathrm{ZrC}_{x} \mathrm{O}_{1-x}$ and $\mathrm{t}, \mathrm{c}-\mathrm{ZrO}_{2}$. The phases of $\mathrm{t}, \mathrm{c}-\mathrm{ZrO}_{2}$ and $\mathrm{CaZrO}_{3}$ were then reduced to $\mathrm{ZrC}_{x} \mathrm{O}_{1-x}$, which was subsequently reduced to $\mathrm{ZrC}$ by the removal of oxygen and in situ carbonization.
\end{abstract}

Keywords: $\mathrm{ZrC}$; electrochemical; $\mathrm{ZrO}_{2}$; molten salt

\section{FULL TEXT}

(C) 2020 The Authors. Published by ESG (www.electrochemsci.org). This article is an open access article distributed under the terms and conditions of the Creative Commons Attribution license (http://creativecommons.org/licenses/by/4.0/). 